Toolbox

Editor's Note: Toolboxes are intended to briefly highlight and evaluate an emerging approach or a resource that is becoming widely used in neuroscience. For more information, see http://www.jneurosci.org/misc/itoa.shtml.

\title{
Investigating Axonal Guidance with Microdevice-Based Approaches
}

\author{
Isabelle Dupin, ${ }^{1,2}$ Maxime Dahan, ${ }^{3}$ and Vincent Studer ${ }^{1,2}$ \\ ${ }^{1}$ Université de Bordeaux, Interdisciplinary Institute for Neuroscience, Unité Mixte de Recherche 5297, F-33000 Bordeaux, France, ${ }^{2}$ Centre National de la \\ Recherche Scientifique, Interdisciplinary Institute for Neuroscience, Unité Mixte de Recherche 5297, F-33000 Bordeaux, France, and ${ }^{3}$ Laboratoire Physico- \\ Chimie, Institut Curie, Centre National de la Recherche Scientifique-Unité Mixte de Recherche 168, Université Pierre et Marie Curie-Paris 6, 75248 Paris \\ Cedex 05, France
}

The precise wiring of the nervous system relies on processes by which axons navigate in a complex environment and are guided by a concerted action of attractive and repulsive factors to reach their target. Investigating these guidance processes depends critically on our ability to control in space and time the microenvironment of neurons. The implementation of microfabrication techniques in cell biology now enables a precise control of the extracellular physical and chemical environment of cultured cells. However, microtechnology is only beginning to be applied in the field of axon guidance due to specific requirements of neuronal cultures. Here we review microdevices specifically designed to study axonal guidance and compare them with the conventional assays used to probe gradient sensing in cell biology. We also discuss how innovative microdevice-based approaches will enable the investigation of important systems-level questions on the gradient sensing properties of nerve cells, such as the sensitivity and robustness in the detection of directional signals or the combinatorial response to multiple cues.

\section{Introduction}

Neurons send out axons that follow precise paths in the nervous system to reach the correct target and establish proper connections. Axon guidance processes are fundamental during development and for regeneration after an injury. Axonal navigation is mediated by the growth cone (GC), a highly motile structure located at axonal tip with the ability to sense directional signals from the extracellular environment and to induce axonal response (Mortimer et al., 2008). In vivo studies in different animal models, further complemented by in vitro studies, have provided essential knowledge on guidance cues implicated in brain wiring (Kolodkin and Tessier-Lavigne, 2011). Such molecules, notably members of the netrin, semaphorin, ephrin, and slit families, as well as cell-adhesion molecules, morphogens and growth factors, promote the oriented growth of axons through the graded distribution of substrate-bound or diffusible factors. How neurons

Received July 31, 2013; revised 0ct. 8, 2013; accepted 0ct. 9, 2013.

This work was supported by grants from the Agence Nationale pour la Recherche (ANR Piribio Cone, ANR Corridor) and by the Fondation Pierre-Gilles de Gennes. We thank Sonia Garel, Ludmilla Lokmane, Ammar Azioune, and Andrew Penn for helpful discussions and comments on the manuscript.

M.D. and V.S. are scientific founders of Alveole, a start-up company developing microsystems for cell-based assays. I.D. declares no competing financial interests.

Correspondence should be addressed to Vincent Studer, UMR5297-CNRS/Université Bordeaux, Interdisciplinary Institute for Neuroscience, 146, rue Léo Saignat, F-33077 Bordeaux Cedex, France. E-mail: vincent.studer@u-bordeaux2.fr.

DOI:10.1523/JNEUROSCI.3277-13.2013

Copyright $\odot 2013$ the authors $\quad 0270-6474 / 13 / 3317647-09 \$ 15.00 / 0$ translate intracellularly the asymmetry of the extracellular environment is another key aspect of neuronal chemotaxis. Identification and regulation of the receptors involved in signal transduction and intracellular signalization has been investigated intensively over past decades. In parallel, important advances have been made in understanding the basic mechanisms of GC steering, including the role of the cytoskeleton, cell adhesion, membrane trafficking, transcription, and translation. (Jung et al., 2012; Vitriol and Zheng, 2012).

Several in vitro assays have been developed to decipher the mechanisms controlling the different aspects of neurite turning and have played a decisive role in the identification of guidance cues and the characterization of their effects. However, despite considerable progress in our understanding of neuronal chemotaxis, an integrative view of GC guidance is still lacking. For example, the ability of GCs to amplify and filter external signals or to adapt to temporally changing environments remains poorly investigated. This is largely due to the difficulty in performing a quantitative analysis in conventional in vitro assays.

An ideal guidance assay should satisfy several conditions: (1) cue gradients should be precisely controlled in space and time, (2) the assay should be easily compatible with neuronal culture methods and with live cell imaging, and (3) the assay should be amenable to large throughput acquisition. In recent years, the need to meet these criteria has led to novel approaches based on microtechnology, namely the set of fabrication techniques at the 
micron scale. Thanks to their unparalleled capability to tailor the extracellular environment (liquid and/or surface bound), microsystems now open the way to advanced guidance assays. Starting from a recall of conventional methods, the purpose of this review is to describe the novel microdevices that now bring us closer to the ideal conditions described above. We argue that these technological advances will enable the investigation of new biological questions on neuronal chemotaxis.

\section{Coculture assays: from the classical 3D coculture assay to $3 \mathrm{D}$ quantitative coculture assays}

Classical 3D coculture assay

In the initial version of the coculture assay, an explanted tissue containing developing neurons is cultured together with a target tissue in semisolid matrices such as collagen gels or plasma clots (Ebendal and Jacobson, 1977). Validation of the hypothesis of attraction or repulsion is most of the time deduced from the final distribution and length of axons (Fig. 1A). Pioneering studies were performed on the guidance of developing trigeminal sensory axons (Lumsden and Davies, 1983, 1986) and spinal commissural axons (Tessier-Lavigne et al., 1988; Placzek et al., 1990). Identification and cloning of the genes coding for putative guidance factors have led to a modified version of the coculture assay in which the explant is cultured with transfected cells expressing the factor of interest (Dazert et al., 1998). Advantages of this assay include the direct visualization of the result and the possibility to test a high number of GCs in the same experiment. However, conclusions about the attractive or other guidance nature of the cue depend on the symmetry of the explant and precisely positioning the explant near the target tissue is delicate. Furthermore, live imaging of growing axons in this assay is difficult and the conclusion is deduced from the final state of the explant 1 or $2 \mathrm{~d}$ after positioning it. Distinguishing between a growth-promoting effect and a chemotactic effect can be done by computational analysis, whereas distinguishing between an asymmetric neurite initiation promoting effect and a chemotactic effect requires supplementary experiments such as delaying gradient application to allow neurite growing from the explants (Lumsden and Davies, 1983; Mortimer et al., 2010). Moreover, the exact cue concentration released by the cells in the target tissue and the shape of the gradient are both unknown.

\section{D quantitative coculture assay}

A 3D quantitative assay was developed to generate precise, reproducible, and stable gradients (Rosoff et al., 2004). Lines of increasing amounts of guidance molecules are printed on top of a thin collagen gel in which explants have been embedded (Fig. $1 B$ ). After a relatively short time, typically $3 \mathrm{~h}$, a smooth gradient independent of the depth is created by diffusion of the molecules into the gaps between the lines (Fig. $1 B$ ). With this method, dorsal root ganglion (DRG) neurons were shown to respond to nerve growth factor (NGF) gradients with a high sensitivity but within a narrow range of NGF concentrations (Rosoff et al., 2004). Nevertheless, this assay is limited to gradients of low steepness ( $\sim 0.1 \%$, the steepness being defined as the relative change in concentration along the width of the growth cone) and requires relatively expensive equipment. A simpler device based on a dual compartment chamber overcomes the problems of cost and gradient steepness. It uses diffusion over a precise distance from a fixed reservoir to explants embedded in collagen gel to form stable and controlled gradients (Pujic and Goodhill, 2013). Using this assay, steeper gradients $(0.4-1.2 \%)$ can be generated and robust responses of DRG neurons to NGF and olfactory bulb neurons to Slit2 were observed. Another recent device based on a microfluidic network proposes an interesting solution to circumvent the problem of explants and target cells positioning in the conventional coculture assay (Tharin et al., 2012). The system consists of a central chamber surrounded by two side compartments containing the potential target explanted tissues. The neurons of interest, which can be very small in number, are seeded in a $3 \mathrm{D}$ gel in the central compartment. Importantly, the device is compatible with live-cell imaging and permits the evaluation of the effects of distinct target tissues on axon guidance. For example, this technique was used to demonstrate the preferential growth of corticospinal motor neurons toward a spinal cord explant rather than a cerebellum explant. Although the distinction between a trophic and a guidance effect is still difficult to achieve in these assays, they represent significant advances in the quantitative evaluation of axon guidance.

\section{Assays for localized sources of guidance cues: from the micropipette-based assay to optical uncaging of caged molecules \\ Micropipette-based assay}

The widely used micropipette assay has been instrumental in characterizing the newly discovered axon guidance cues and the associated intracellular pathways. It relies on the pulsating release of guidance cues from a micropipette. The tip of the pipette, commonly placed at $45^{\circ}$ from the axon's longitudinal axis (Fig. $1 C$ ), acts as a local source of signaling cues (Lohof et al., 1992) and induces a cue gradient across the GC (Gundersen and Barrett, 1979). The first study using this method showed that chick dorsal-root axons are attracted by NGF (Gundersen and Barrett, 1979). Importantly, the pipette can be moved along the experiment to adapt to growth displacement (Gundersen and Barrett, 1979). Despite its ease of use, two major disadvantages are associated with this technique. First, only one cell at a time can be exposed to the gradient, meaning that this assay is not compatible with high-throughput experimentation. Second, the stimulation is not well controlled, leading to poorly reproducible experiments: the concentration seen by the GC strongly depends on the molecular weight of the guidance factor and there is not always a linear relationship between the amount ejected and the pulse duration or pulsing frequency (Pujic et al., 2008). As a result, the micropipette-based assay only enables a qualitative estimate of the axonal response to a cue gradient. Interestingly, the principle of the pipette-based assay has been integrated on a device with microfluidic valves to produce dynamic gradients, but it has yet to be applied to axon guidance studies (Chung et al., 2006).

\section{Optical uncaging of caged molecules or encapsulated molecules} Photorelease techniques provide interesting alternatives to creating local sources of guidance signals. A caged guidance factor (i.e., a light-sensitive version of the molecule) can be locally and precisely released ("uncaged") inside or in proximity to the GC (Ellis-Davies, 2007; Fig. 1D). This technique offers the advantage of very good temporal and spatial control of the stimulation and the capacity to define the stimulation extracellularly or intracellularly (Ellis-Davies, 2007). The major limitation is the low number of available caged molecules. So far, mechanisms underlying GC turning have been investigated using caged compounds such as caged-calcium (Gomez and Spitzer, 1999) and $\mathrm{IP}_{3}$ (Akiyama et al., 2009), but to our knowledge, no guidance factor exists in a caged form. Recent publications describe a promising method for delivering a controlled number of molecules (Sun and Chiu, 2003; Kress et al., 2009; Pinato et al., 2011). Guidance factors are 


\section{CO-CULTURE GUIDANCE ASSAYS}

A Classical co-culture assay

Day $0 \quad$ Top view

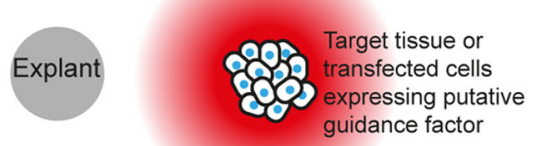

Day 1 or 2
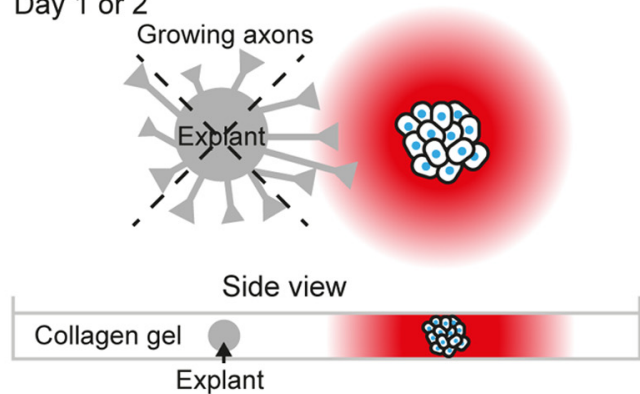

B 3D quantitative assay

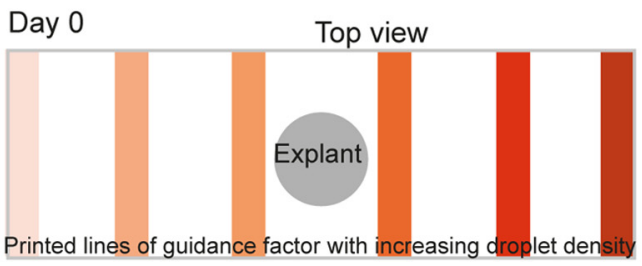

Day 1 or 2

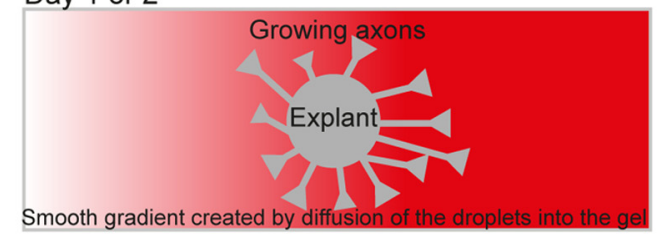

Side view

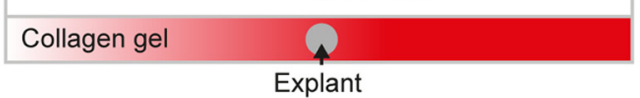

\section{ASSAYS FOR LOCALIZED SOURCES OF GUIDANCE CUES}

C Micro-pipette based assay

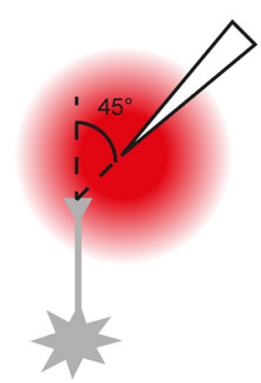

D Optical uncaging of caged molecule

Caging

- chromophore

Caged molecule

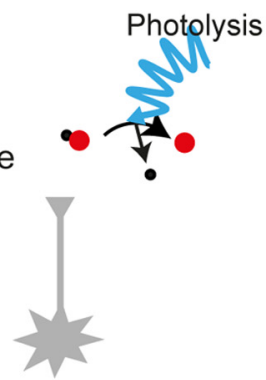

E $\begin{gathered}\text { Photorelease of } \\ \text { encapsulated molecules }\end{gathered}$

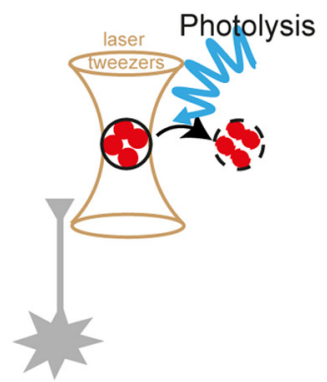

\section{ASSAYS FOR DIFFUSIBLE GUIDANCE CUES}

F Dunn chamber
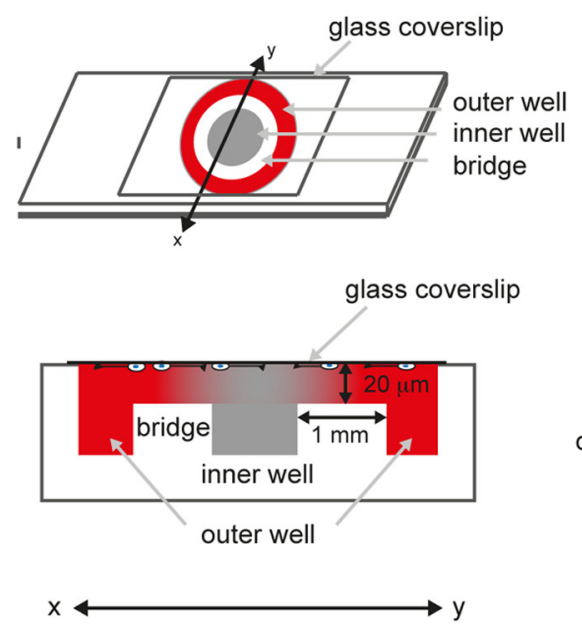

$G$ «Shear-free» microfluidic device
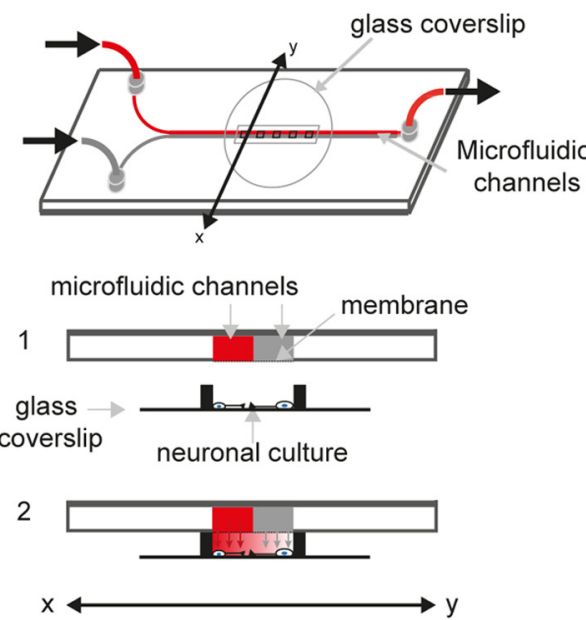

$\mathrm{H}$ «Neuron-benign» microfluidic gradient generator
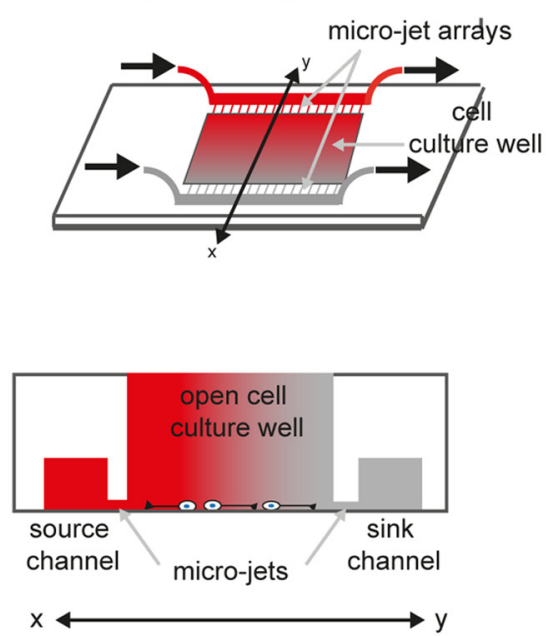

Figure 1. Top, Coculture assays. $A$, The classical $3 \mathrm{D}$ coculture assay consists of an explant embedded in a gel exposed to a target tissue or transfected cells expressing a putative guidance factor. $\boldsymbol{B}$, In the 3D quantitative coculture assay described by Rosoff et al. (2004), lines of guidance factor are printed with an increasing droplet density on top of a collagen gel-containing explants. The diffusion of the molecule creates a smooth and predictable gradient after few hours. Middle, Assays for localized sources of guidance cues. C, In the classical (Figure legend continues.) 
encapsulated in lipid vesicles and positioned in the vicinity of the GC with optical tweezers (Pinato et al., 2012; Fig. 1E). UV pulses induce the breakdown of the vesicle and the release of the molecules. Using this method, the minimal number of Netrin-1 and Sema3A molecules to induce an attraction and a repulsion, respectively, in hippocampal neurons has been determined (Pinato et al., 2012).

\section{Assays for diffusible cues: from the Dunn chamber to microfluidic devices}

Dunn chamber

The Dunn chamber consists of a central circular chamber and an outer annular chamber separated by an annular bridge (Zicha et al., 1991; Fig. 1F). The geometry, in particular the height between the bottom of the bridge and the coverslip $(20 \mu \mathrm{m})$ and the length of the bridge ( $1 \mathrm{~mm})$, are known, so the shape of the gradient can be calculated (Zicha et al., 1991). Depending of the molecular mass of the factor tested, the gradient can remain stable for several hours (Zicha et al., 1991). The use of the Dunn chamber with neuronal cultures was first demonstrated in a study (Maden et al., 1998) showing that retinoic acid is a chemotactic agent for chick dorsal spinal cord neurons. The Dunn chamber has since become a popular tool for guidance studies, in particular due to the possibility of visualizing, in real time, the response of multiple neurons (Yam et al., 2009; Dudanova et al., 2010; Bai et al., 2011; Dudanova et al., 2012; Yam et al., 2012). Nevertheless, the system is limited to dissociated cells and is not very flexible: the stimulation cannot be easily controlled in time and the gradient shape (almost linear) cannot be modified.

\section{Microfluidic devices}

Microfluidics provides an ideal tool to manipulate small volumes of liquids precisely, typically from the nanoliter to the microliter. Numerous microfluidic platforms have been developed to apply gradients controlled in space and time to cultured cells (Keenan and Folch, 2008; Kim and Wu, 2012), but here we will restrict our discussion to the applications of microfluidic devices in the context of axon guidance. One of the first devices developed and applied for neuronal guidance is composed of free and forcedchoice regions (Wittig et al., 2005). The device consists of a Y-shaped microchannel. The forced-choice point is localized at the split in the Y-shaped microchannel. Neuronal cultures are placed in the presentation region, where they encounter a broad range of concentrations before eventually going into the forcedchoice region. Gradient slope and shape are quantified and depend on the flow rate in the microchannels. This assay has been used to confirm that neonatal spiral ganglion neurons from the rat cochlea preferentially grow toward a source of neurotrophin-3 (NT-3; Wittig et al., 2005). The device is compatible with explant culture and the

\section{$\leftarrow$}

(Figure legend continued.) micropipette-based assay, the micropipette steadily releases a putative guidance cue in the vicinity of the GC. The tip of the micropipette is placed $45^{\circ}$ to the axon's longitudinal axis. $\boldsymbol{D}$, Light-sensitive molecules can be activated locally by photolytic uncaging inside or near the GC. $E$, A controlled number of molecules can be encapsulated in vesicles, which are trapped by optical tweezers and placed in proximity of the GC. Photolysis induces the local release of the molecules. Bottom, Assays for diffusible cues. $\boldsymbol{F}$, In the Dunn chamber the putative guidance cue is placed in the outer annular chamber. The culture coverslip is inverted onto the slide. Neurons are subjected to an almost linear gradient. $\mathbf{G}$, In the shearfree microfluidic device, the $Y$-shaped fluidic microcircuit is interfaced via a semipermeable membrane with cell cultured in microwells (Morel et al., 2012). $\boldsymbol{H}$, In the neuron-benign microfluidic generator, neurons are cultured in an open reservoir (Bhattacharjee et al., 2010). Two arrays of small channels called microjets feed the reservoir, resulting in the formation of a steady-state gradient while avoiding high shear stress for the neurons. tissue culture plate is reusable, but neurons are exposed to the flow and therefore undergo shear stress. Because GC collapse is observed even under moderate flow (Joanne Wang et al., 2008), shear stress represents a major concern in the use of microfluidics in neurobiology.

To overcome this limitation, different solutions have been proposed. The so-called composite-gradient generator uses microwell structures to protect neurons from shear stress. The incorporation of pneumatic valves allows the generation of gradients of various shapes and slopes (Joanne Wang et al., 2008). The device proposed by Bhattacharjee et al. (2010) consists of a cell culture reservoir that is constantly fed laterally by two arrays of small channels called microjets, resulting in the formation of a steady-state gradient at the surface of the reservoir (Fig. $1 H$ ). Because the microjets are directed upward, the cells do not experience high shear stress. The gradient can potentially be changed by adjusting the localization and/or the orientation of the microjets. In another microfluidic platform (Kothapalli et al., 2011), neurons are cultured in a physiological 3D hydrogel that is placed in contact with two channels acting as source and sink for guidance factors; this method also offers the advantage of reducing shear stress. In contrast to the classical coculture assay (see part 1), the neurons are exposed to a stable quantified gradient. To overcome shear stress, a different solution was proposed by Morel et al. (2012): a semipermeable membrane separates the microfluidic channels, which can be used to generate a concentration profile from the cell culture chamber and acts as a hydraulic barrier (Fig. 1G). The solution flowing in the microchannels penetrates the culture chamber by diffusion through the membrane pores.

Beyond shear stress, using microfluidics for axonal guidance experiments raises a second issue: mammalian neurons are very sensitive and are difficult to maintain viable during several days in small closed microenvironments with limited gas and nutrient exchange. Specific adaptations of the culture methods and/or the microdevice are usually required. In the platform developed by Bhattacharjee et al. (2010), neurons are cultured in an open reservoir (Fig. $1 H$ ). Mouse hippocampal and DRG neurons can also be cultured directly in the device under the condition that they are seeded in a 3D gel (Kothapalli et al., 2011). The device of Morel et al. (2012) offers the advantage of isolating the culture system from the microfluidic system, these two components being put together only at the onset of the experiment (Fig. 1G). This avoids the need to adapt neuronal culture conditions to small closed microenvironments.

Although most of the microfluidic devices developed for axon guidance have been used for proof of concept (Wittig et al., 2005; Bhattacharjee et al., 2010; Kothapalli et al., 2011), a few examples illustrate how a microdevice can advance our understanding of axon guidance. These include the response of Xenopus spinal neurons to single and composite gradients of guidance cues (Joanne Wang et al., 2008) and the process of GABA receptors polarization, signal amplification, and filtering in the GC at the single molecule level (Morel et al., 2012). However, it is clear that further investigations will emerge from ongoing and future collaborations between neurobiologists and bioengineers.

\section{Assays for substrate-bound cues: from the stripe assay to continuous substrate-bound gradients generating devices} GCs are not only directed by soluble gradients but also by substrate-bound gradients. Specific in vitro assays have been designed to assess GC responses to immobilized guidance cues (for an extensive review, see Roy et al., 2013). 


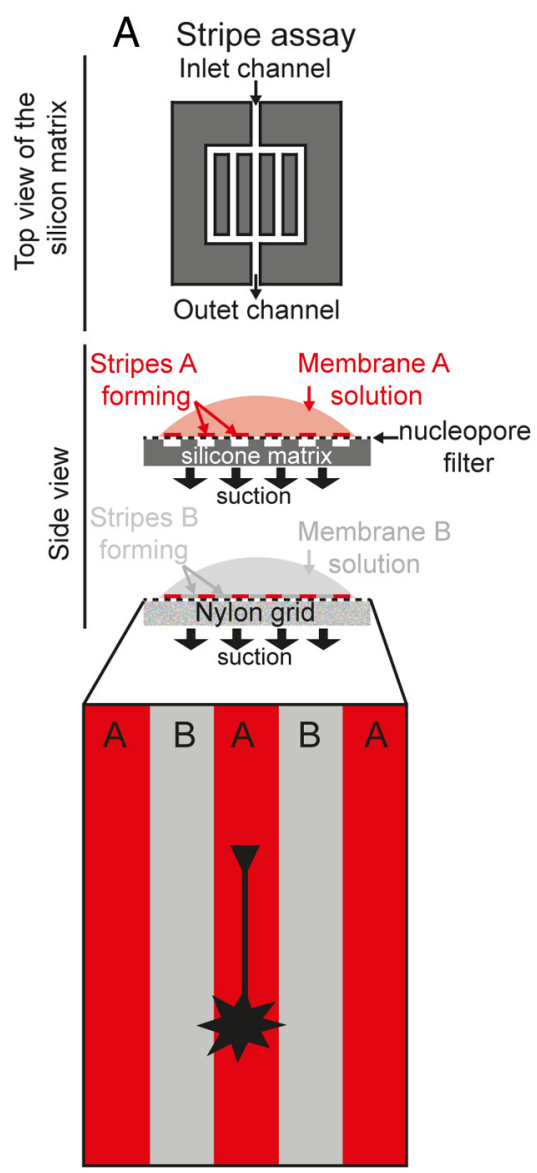

B Discontinous gradient

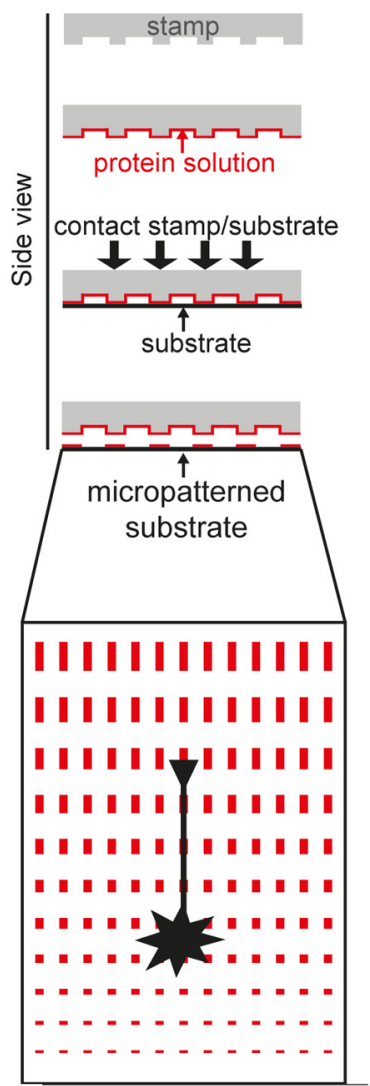

C Continous gradient

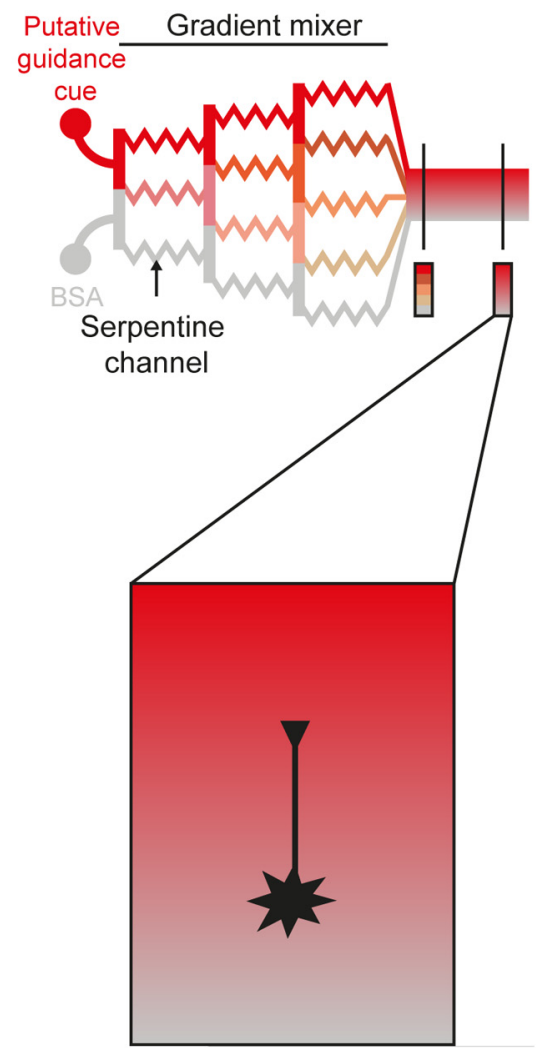

Figure 2. Assays for substrate-bound cues. $A$, The stripe assay tests the response of growing neurons to two different substrate-bound molecules presented as alternating lines. $\boldsymbol{B}, \mathrm{A}$ discontinuous gradient can be produced by microcontact printing. In this example, neuronal cells are challenged by patterns of rectangles with increasing sizes (von Philipsborn et al., 2006a). C, Continuous gradients can be formed in solution by a gradient mixer. The proteins are absorbed in the final channel on a poly--lysine-coated surface and neurons are plated on this substrate-bound gradient (Dertinger et al., 2002).

\section{Stripe assays}

The original stripe assay was developed in the 1980s to test the preference of growing axons for different cell membrane preparations (Walter et al., 1987). Alternating stripes of cell membrane fractions are created on a surface using a silicone matrix containing parallel microchannels (Fig. 2A). The type A membrane fragments circulate inside the microchannels and are sucked onto a Nucleopore filter by application of a vacuum. After removing the silicone matrix, the type B membrane fragments are deposited on the filter and collect only in the stripes with no type A fragment, resulting in alternating stripes of type $\mathrm{A}$ and $\mathrm{B}$ membranes (Fig. $2 A$ ). The neurons extending on these so-called carpets are confronted with the two different substrates. If the axons have a preference for one of the two substrates, a striped outgrowth can be observed after 1 or $2 \mathrm{~d}$ in culture (Fig. $2 A$ ). In this original version, this in vitro assay has been used to understand the establishment of the topographic map in the chick retinotectal system (Walter et al., 1987; Parent and Devreotes, 1999; Walter et al., 1987). In a modified version of this assay, soluble proteins instead of membrane fractions are bound to the substrate (Vielmetter et al., 1990). Because the stripe assay requires little amounts of proteins or membrane fractions and the result is easy to read, this assay represents a very convenient tool to assess axon guidance. It has been widely used to understand guidance mechanisms in various systems, such as the thalamocortical system (Mann et al., 1998), the olfactory system (Savaskan et al., 1999; Knöll et al.,
2001), and the hippocampus (Knöll et al., 2006). However, the results have to be interpreted carefully: striped outgrowth can only reflect a preference for one of the two substrates and it does not necessarily mean that the preferred substrate is attractant or the avoided stripe repulsive. In addition, homogenous presentation of the putative guidance cue in the stripe, as well as the abrupt transitions between lines, probably do not reflect the distribution of guidance factors in vivo. Smooth variations of protein density at the surface represent a major challenge in in vitro assays for substrate-bound cues.

\section{Assays for discontinuous gradient of substrate-bound cues}

Patterning of the culture substrate can be achieved using ink-jet printing by a so-called microdispenser apparatus. Laminin patterns to support neuronal growth can be generated with this technique (Turcu et al., 2003). By changing the number of drops per point, discontinuous gradients can be created (Gustavsson et al., 2007). The technique is fast and does not involve lithographic methods requiring equipment not usually present in neuroscience laboratories. The main drawbacks include the low spatial resolution and a lower quality of the micropatterns on glass substrate compared with plastic surfaces, which raises a problem for fluorescence imaging. Discontinuous gradients can also be generated by microcontact printing (von Philipsborn et al., 2006a). This technique uses the relief patterns on a stamp (usually made of polydimethylsiloxane [PDMS]) to print patterns on a sub- 
strate through contact (Fig. 2B). Patterns of dots and lines with varying sizes and spacings can be used to produce discontinuous gradients (von Philipsborn et al., 2006a; Fig. 2B). The advantage is that these patterns are stable over a long time. This assay has been instructive to understand how the zone where the temporal chick retinal ganglion cells axons stop is defined in a substratebound ephrin gradient (von Philipsborn et al., 2006b). However, microcontact printing does not allow the deposition of different concentrations simultaneously. Mixed techniques using microfluidics and microcontact printing have been used to overcome these difficulties (von Philipsborn et al., 2007) Increasing protein concentrations are injected through parallel channels system onto a PDMS surface. The stepwise protein-bound gradient is then transferred by microcontact printing of the PDMS stamp onto the culture dish. The results previously obtained by the technique of microcontact printing (von Philipsborn et al., 2006a) were essentially confirmed with this method (Lang et al., 2008). Although very informative, these assays only produce discontinuous gradients.

\section{Assays for continuous gradient of substrate-bound cues}

The first continuous substrate-bound gradients were produced by injecting a solution of putative guidance factor solution into a drop of Hank's solution (Halfter, 1996). The proteins radially diffuse and get adsorbed on the substrate. This pioneering work provided a basis for studying axon guidance by immobilized gradients but also underlined the need for a better spatial control of the gradient and a higher reproducibility of the pattern. Microfluidic gradients mixers can fulfill these requirements: continuous gradients of proteins like laminin or chondroitin sulfate proteoglycan can be generated with good accuracy (Dertinger et al., 2002; Li et al., 2008; Fig. 2C). After adsorption of these proteins onto a poly-L-lysine-coated substrate, neurons are plated and cultured on these substrate-bound gradients (Fig. 2C). Double-cue gradients have also been created using this method (Li et al., 2008). The creation of these gradients requires relatively fast flow in the channels, so cell plating cannot be done before protein adsorption. A new technique called diffusive printing offers an alternative solution to create immobilized protein gradient (Mai et al., 2009). The protein solution is injected into the channels of a removable hydrogel matrix stamp in contact with an epoxy-coated glass coverslip. While proteins are diffusing in the gel, they can covalently bind the epoxy-coated glass substrate, resulting in stable bound gradients once the stamp is removed. Similarly to the gradients generated by microfluidic mixer described previously, neurons are plated after gradient creation.

Photoimmobilization techniques are promising techniques to create high-resolution gradients of substrate-bound cues, in which the intensity of the light modulates the density of the molecule at the surface (Herbert et al., 1997). Using this technique, DRG neurons were shown to turn and migrate up a gradient of an adhesive laminin peptide (Adams et al., 2005). Laser-assisted protein adsorption by photobleaching is another method used to create gradients of immobilized guidance factors (Bélisle et al., 2008). The principle of the method relies on the photobleaching of fluorescently tagged molecules to generate patterns. This technique has been used to assess neurite attraction of neuron-like cells in laminin-1 gradients and is compatible with high-content screening requirements (Bélisle et al., 2012). The generation of substrate-bound gradients undoubtedly allows more precise characterization of neuronal answers to graded signals, but so far they are lacking a temporal control that can be easily implemented with microfluidic devices.

\section{Assays for physical cues}

Most of the work in the field of axon guidance has focused on the role of chemical signals in GC directional decisions. However, mechanical cues could also play an important role in the decision-making process, and the application of microfabrication techniques in biology has been very useful in proving that physical constraints can strongly affect neurite outgrowth and guidance. The direct-writing electron beam lithographic process allows the creation of microgrooved substrates on which Xenopus neurons and rat hippocampal neurons can grow (Rajnicek et al., 1997). Directional preference depends on species (Xenopus vs rat) and on neuronal age (Rajnicek et al., 1997). Investigation of the signaling pathway implicated in perpendicular guidance has led to the identification of calcium and protein kinase $\mathrm{C}$ signaling (Rajnicek and McCaig, 1997). More recently, it was shown that neuroblasts from the CNS, but not from the peripheral nervous system, exhibit both perpendicular and parallel guidance on microstructured grooves, reinforcing the idea that microgrooveinduced guidance is cell-type dependent (Nagata et al., 1993). Physical constraints can be combined with biochemical variations of substrate coating (Li and Folch, 2005) or with gradients of diffusible cues (Kundu et al., 2013). Axon-turning decisions result in the integration of topographical features and biochemical cues (Li and Folch, 2005; Kundu et al., 2013). Standard photolithographic methods can also be used to create 3D constraints on silicon chips used as substrates for neuronal culture (Francisco et al., 2007). A GC interacting with a wall of a microfabricated chamber shows a decrease in GC area, further suggesting that neurons sense physical constraints. axon-turning capacity around corners in corridor depends on the angle of the corner and the corridor width. In good agreement with the findings that neurons sense and respond to physical cues, it was recently shown that chick DRG neurites preferentially grow down a gradient of stiffness in a 3D environment (Sundararaghavan et al., 2009). The principle of this assay relies on the exposure of neurons embedded in a 3D collagen gel in a microfluidic system to a gradient of genipin, a natural cross-linker of the collagen. The gradient of genipin creates a gradient of stiffness for the cells. Altogether, these in vitro systems have led to the idea that substrate topography not only needs to be permissive for axon growth, but also gives important directional inputs to the GC.

\section{Emerging questions using innovative approaches}

The advent of microfabrication-based technologies does not simply expand the arsenal of techniques available to neuroscientists. More importantly, it opens the way for investigation of the important questions on axonal guidance that have so far remained largely unexplored, essentially due to a lack of appropriate experimental tools. As discussed below in a nonexhaustive list of examples, the ability to accurately control the spatial and temporal profile of guidance cues should be especially beneficial for systems-level studies of the sensing properties of GCs.

\section{Amplification, filtering, and adaptation during gradient sensing} Similarly to leukocyte or amoeba chemotaxis, the accuracy of the axonal guidance response likely depends on the absolute concentration of chemoattractant and the shape and steepness of the gradient (Tessier-Lavigne and Placzek, 1991; Fig. 3A). In addition, GCs face an environment that constantly evolves in terms of the nature and concentration of the external cues or the spatial orientation of their graded signals. Therefore, they must adapt their response to dynamically changing stimulations. Furthermore, the transduction of signals by the sensing machinery (re- 


\section{A Quantification of axon sensitivity}

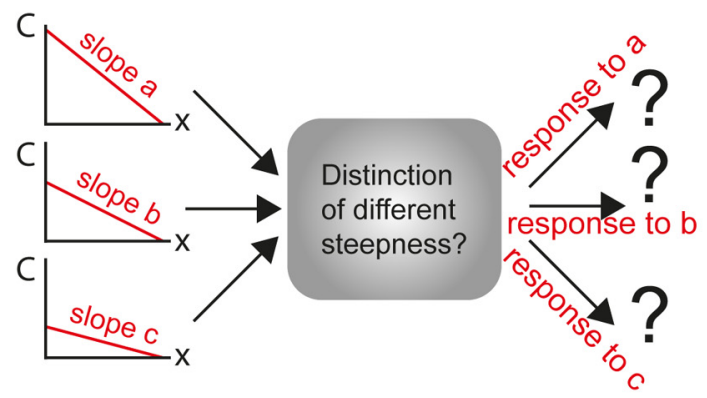

$a>b>c$

\section{Spatial and temporal noise filtering}

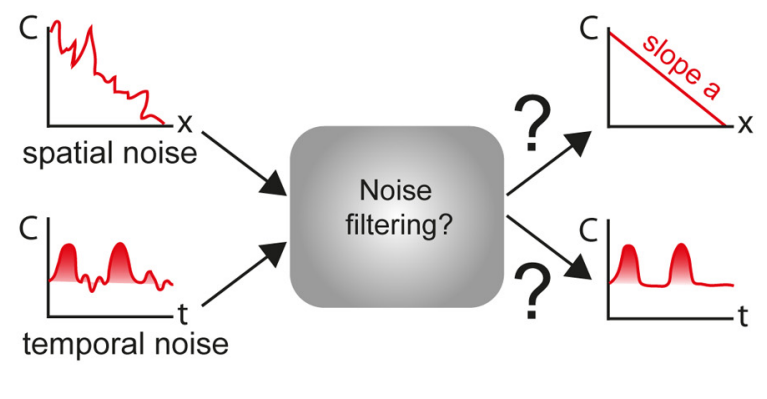

D Combinatorial effects

\section{B Adaptation}
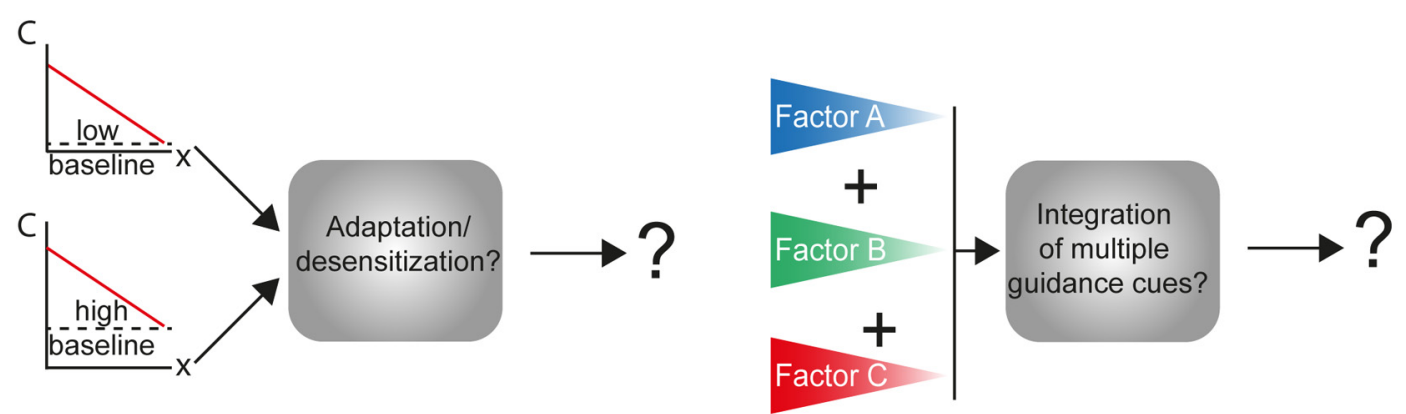

Figure 3. Emerging questions to address using innovative devices. $\boldsymbol{A}$, Potential distinction of gradients of different steepness by the $G C$. $\boldsymbol{B}$, Existence or absence of an adaptation/desensitization phenomenon in GC response to molecular cues. C, Spatial and temporal noise filtering enabling the GC to reproducibly navigate in a noisy environment. $\boldsymbol{D}$, The integration of multiple cues by the axon with potential combinatorial effects.

ceptors and downstream effectors) is an intrinsically stochastic process. All of these points raise important, and still unresolved, issues on the ability of GCs to process chemical signals in space and in time. One of the key problems is determining the sensitivity of gradient sensing - in other words, the minimal concentration difference across the GC that elicits a directional response. Although it is generally considered that non-neuronal cells can respond to a gradient with steepness down to $\sim 2 \%$ (Parent and Devreotes, 1999; Firtel and Chung, 2000), a thorough evaluation of GC sensitivity requires cells to be submitted to a set of gradients with varying slope and concentration. This has been done in two pioneering studies for substrate-bound ephrin gradients (von Philipsborn et al., 2006b) and diffusible NGF gradients (Mortimer et al., 2009; Fig. 3A). In addition, it is essential to probe the response of neurons to fluctuating signals and thereby evaluate their capacity to filter out noise from true directional information (Fig. 3C). Understanding the dynamics of the GC response will also be key to analyzing adaptation processes, the ability of the cell to reset its sensitivity to the basal state of its chemical environment (Fig. 3B).

Conventional assays, such as the micropipette-based-assay, the Dunn chamber, or the coculture assay, clearly lack the level of gradient control or the throughput required to address all of the issues mentioned above. In contrast, a few quantitative microdevice-based assays have already provided a comprehensive description of the axonal response, including the different steps of signal amplification, noise filtering, and adaptation. For example, varying both the gradient slope and the absolute concentration of NGF (Rosoff et al., 2004) led to the conclusion that guidance strategy (i.e., biased turning vs growth modulation) depends on gradient steepness (Mortimer et al., 2010). Data from the same assay (Rosoff et al., 2004) have also been used to build a GC-sensing model consistent with an absence of adaptation (Xu et al., 2005). In another study, analysis of the polarized distribution of chemoreceptors at the GC surface in response to controlled microfluidic gradients showed that GCs acted as signal amplifiers and low temporal filters within a narrow range of concentrations, with no evidence for adaptation (Morel et al., 2012). In the future, combining microdevices with live imaging of guidance receptors, chemotactic regulators or effectors, or signaling sensors will surely shed light on new aspects of axon guidance from the molecular to the systems level.

\section{Combinatorics of the axonal response}

A specific feature of neurons compared with other chemotactic systems (e.g., bacteria, amoebas, or leukocytes) is the vast repertoire of signals that induce attractive or repulsive turning. Therefore, it is likely that navigating GCs must integrate multiple guidance cues as they travel inside the brain during development. The rules by which GCs respond to a complex signal composed of multiple guidance factors are currently unclear (Fig. 3D). The different cues can act independently, resulting in additive effects (Dudanova and Klein, 2013), but they can also interact synergistically, leading to nonadditive effects such as the permissive effect of Slit 1 enabling Netrin-1 attractive activity on thalamic neurons (Bielle et al., 2011) or the effect of topographic cues maximizing Netrin-1 answer on hippocampal neurons (Kundu et al., 2013). The combinatorial activities of guidance cues have been poorly examined in vitro, essentially because of the lack of experimental tools allowing these studies. Microfluidic techniques should provide an ideal approach to design systems that allow multicomponent stimulations with appropriate spatial and temporal control 
of the concentration profile of each cue. Furthermore, fluidic microdevices can be combined with surface micropatterning to investigate the crosstalk between diffusible and surface-bound factors (Joanne Wang et al., 2008). Improvement in patterning techniques, and in particular in multiprotein patterning as initiated by the novel double-cue stripe assay (Gebhardt et al., 2012), will surely lead to important advances in understanding the integration of multiple substrate-bound cues.

\section{Conclusion and perspectives}

The integration of microtechnology into neuroscience offers exciting prospects for both fundamental research and therapeutic applications. Pioneering experiments (Taylor et al., 2005; Joanne Wang et al., 2008) have shown how microsystems could be used fruitfully to investigate neuronal growth and turning. However, despite these early successes, the investigation of axonal navigation in microsystems has long been hampered by the difficulty of combining delicate neuronal culture conditions with fluidic microenvironments. Most bioengineering challenges have been progressively solved. Thanks to a new generation of microdevices specifically developed to satisfy the constraints of neurobiology, it is now possible to probe in a quantitative manner the response of individual nerve cells, explants-and, soon, possibly slices (Berdichevsky et al., 2009)—to spatially and temporally controlled graded signals of guidance molecules. These novel microdevice-based assays will undoubtedly shed new light on important aspects of axonal navigation.

\section{References}

Adams DN, Kao EY, Hypolite CL, Distefano MD, Hu WS, Letourneau PC (2005) Growth cones turn and migrate up an immobilized gradient of the laminin IKVAV peptide. J Neurobiol 62:134-147. CrossRef Medline

Akiyama H, Matsu-ura T, Mikoshiba K, Kamiguchi H (2009) Control of neuronal growth cone navigation by asymmetric inositol 1,4,5trisphosphate signals. Sci Signal 2:ra34. CrossRef Medline

Bai G, Chivatakarn O, Bonanomi D, Lettieri K, Franco L, Xia C, Stein E, Ma L, Lewcock JW, Pfaff SL (2011) Presenilin-dependent receptor processing is required for axon guidance. Cell 144:106-118. CrossRef Medline

Bélisle JM, Correia JP, Wiseman PW, Kennedy TE, Costantino S (2008) Patterning protein concentration using laser-assisted adsorption by photobleaching, LAPAP. Lab Chip 8:2164-2167. CrossRef Medline

Bélisle JM, Levin LA, Costantino S (2012) High-content neurite development study using optically patterned substrates. PLoS One 7:e35911. CrossRef Medline

Berdichevsky Y, Sabolek H, Levine JB, Staley KJ, Yarmush ML (2009) Microfluidics and multielectrode array-compatible organotypic slice culture method. J Neurosci Methods 178:59-64. CrossRef Medline

Bhattacharjee N, Li N, Keenan TM, Folch A (2010) A neuron-benign microfluidic gradient generator for studying the response of mammalian neurons towards axon guidance factors. Integr Biol (Camb) 2:669-679. CrossRef Medline

Bielle F, Marcos-Mondéjar P, Leyva-Díaz E, Lokmane L, Mire E, Mailhes C, Keita M, García N, Tessier-Lavigne M, Garel S, López-Bendito G (2011) Emergent growth cone responses to combinations of Slit 1 and Netrin 1 in thalamocortical axon topography. Curr Biol 21:1748-1755. CrossRef Medline

Chung BG, Lin F, Jeon NL (2006) A microfluidic multi-injector for gradient generation. Lab Chip 6:764-768. CrossRef Medline

Dazert S, Kim D, Luo L, Aletsee C, Garfunkel S, Maciag T, Baird A, Ryan AF (1998) Focal delivery of fibroblast growth factor-1 by transfected cells induces spiral ganglion neurite targeting in vitro. J Cell Physiol 177:123129. CrossRef Medline

Dertinger SK, Jiang X, Li Z, Murthy VN, Whitesides GM (2002) Gradients of substrate-bound laminin orient axonal specification of neurons. Proc Natl Acad Sci U S A 99:12542-12547. CrossRef Medline

Dudanova I, Klein R (2013) Integration of guidance cues: parallel signaling and crosstalk. Trends Neurosci 36:295-304. CrossRef Medline

Dudanova I, Gatto G, Klein R (2010) GDNF acts as a chemoattractant to support ephrinA-induced repulsion of limb motor axons. Curr Biol 20: 2150-2156. CrossRef Medline

Dudanova I, Kao TJ, Herrmann JE, Zheng B, Kania A, Klein R (2012) Genetic evidence for a contribution of EphA:ephrinA reverse signaling to motor axon guidance. J Neurosci 32:5209-5215. CrossRef Medline

Ebendal T, Jacobson CO (1977) Tissue explants affecting extension and orientation of axons in cultured chick embryo ganglia. Exp Cell Res 105: 379-387. CrossRef Medline

Ellis-Davies GC (2007) Caged compounds: photorelease technology for control of cellular chemistry and physiology. Nat Methods 4:619-628. CrossRef Medline

Firtel RA, Chung CY (2000) The molecular genetics of chemotaxis: sensing and responding to chemoattractant gradients. Bioessays 22:603-615. CrossRef Medline

Francisco H, Yellen BB, Halverson DS, Friedman G, Gallo G (2007) Regulation of axon guidance and extension by three-dimensional constraints. Biomaterials 28:3398-3407. CrossRef Medline

Gebhardt C, Bastmeyer M, Weth F (2012) Balancing of ephrin/Eph forward and reverse signaling as the driving force of adaptive topographic mapping. Development 139:335-345. Medline

Gomez TM, Spitzer NC (1999) In vivo regulation of axon extension and pathfinding by growth-cone calcium transients. Nature 397:350-355. CrossRef Medline

Gundersen RW, Barrett JN (1979) Neuronal chemotaxis: chick dorsal-root axons turn toward high concentrations of nerve growth factor. Science 206:1079-1080. CrossRef Medline

Gustavsson P, Johansson F, Kanje M, Wallman L, Linsmeier CE (2007) Neurite guidance on protein micropatterns generated by a piezoelectric microdispenser. Biomaterials 28:1141-1151. CrossRef Medline

Halfter W (1996) The behavior of optic axons on substrate gradients of retinal basal lamina proteins and merosin. J Neurosci 16:4389-4401. Medline

Herbert CB, McLernon TL, Hypolite CL, Adams DN, Pikus L, Huang CC, Fields GB, Letourneau PC, Distefano MD, Hu WS (1997) Micropatterning gradients and controlling surface densities of photoactivatable biomolecules on self-assembled monolayers of oligo(ethylene glycol) alkanethiolates. Chem Biol 4:731-737. CrossRef Medline

Joanne Wang C, Li X, Lin B, Shim S, Ming GL, Levchenko A (2008) A microfluidics-based turning assay reveals complex growth cone responses to integrated gradients of substrate-bound ECM molecules and diffusible guidance cues. Lab Chip 8:227-237. CrossRef Medline

Jung H, Yoon BC, Holt CE (2012) Axonal mRNA localization and local protein synthesis in nervous system assembly, maintenance and repair. Nat Rev Neurosci 13:308-324. CrossRef Medline

Keenan TM, Folch A (2008) Biomolecular gradients in cell culture systems. Lab Chip 8:34-57. CrossRef Medline

Kim BJ, Wu M (2012) Microfluidics for mammalian cell chemotaxis. Ann Biomed Eng 40:1316-1327. CrossRef Medline

Knöll B, Zarbalis K, Wurst W, Drescher U (2001) A role for the EphA family in the topographic targeting of vomeronasal axons. Development 128: 895-906. Medline

Knöll B, Kretz O, Fiedler C, Alberti S, Schütz G, Frotscher M, Nordheim A (2006) Serum response factor controls neuronal circuit assembly in the hippocampus. Nat Neurosci 9:195-204. CrossRef Medline

Kolodkin AL, Tessier-Lavigne M (2011) Mechanisms and molecules of neuronal wiring: a primer. Cold Spring Harb Perspect Biol 3: pii:a001727. CrossRef Medline

Kothapalli CR, van Veen E, de Valence S, Chung S, Zervantonakis IK, Gertler FB, Kamm RD (2011) A high-throughput microfluidic assay to study neurite response to growth factor gradients. Lab Chip 11:497-507. CrossRef Medline

Kress H, Park JG, Mejean CO, Forster JD, Park J, Walse SS, Zhang Y, Wu D, Weiner OD, Fahmy TM, Dufresne ER (2009) Cell stimulation with optically manipulated microsources. Nat Methods 6:905-909. CrossRef Medline

Kundu A, Micholt L, Friedrich S, Rand DR, Bartic C, Braeken D, Levchenko A (2013) Superimposed topographic and chemical cues synergistically guide neurite outgrowth. Lab Chip 13:3070-3081. CrossRef Medline

Lang S, von Philipsborn AC, Bernard A, Bonhoeffer F, Bastmeyer M (2008) Growth cone response to ephrin gradients produced by microfluidic networks. Anal Bioanal Chem 390:809-816. CrossRef Medline

Li GN, Liu J, Hoffman-Kim D (2008) Multi-molecular gradients of permis- 
sive and inhibitory cues direct neurite outgrowth. Ann Biomed Eng 36: 889-904. CrossRef Medline

Li N, Folch A (2005) Integration of topographical and biochemical cues by axons during growth on microfabricated 3-D substrates. Exp Cell Res 311:307-316. CrossRef Medline

Lohof AM, Quillan M, Dan Y, Poo MM (1992) Asymmetric modulation of cytosolic cAMP activity induces growth cone turning. J Neurosci 12: 1253-1261. Medline

Lumsden AG, Davies AM (1983) Earliest sensory nerve fibres are guided to peripheral targets by attractants other than nerve growth factor. Nature 306:786-788. CrossRef Medline

Lumsden AG, Davies AM (1986) Chemotropic effect of specific target epithelium in the developing mammalian nervous system. Nature 323:538539. CrossRef Medline

Maden M, Keen G, Jones GE (1998） Retinoic acid as a chemotactic molecule in neuronal development. Int J Dev Neurosci 16:317-322. CrossRef Medline

Mai J, Fok L, Gao H, Zhang X, Poo MM (2009) Axon initiation and growth cone turning on bound protein gradients. J Neurosci 29:7450-7458. CrossRef Medline

Mann F, Zhukareva V, Pimenta A, Levitt P, Bolz J (1998) Membraneassociated molecules guide limbic and nonlimbic thalamocortical projections. J Neurosci 18:9409-9419. Medline

Morel M, Shynkar V, Galas JC, Dupin I, Bouzigues C, Studer V, Dahan M (2012) Amplification and temporal filtering during gradient sensing by nerve growth cones probed with a microfluidic assay. Biophys J 103: 1648-1656. CrossRef Medline

Mortimer D, Fothergill T, Pujic Z, Richards LJ, Goodhill GJ (2008) Growth cone chemotaxis. Trends Neurosci 31:90-98. CrossRef Medline

Mortimer D, Feldner J, Vaughan T, Vetter I, Pujic Z, Rosoff WJ, Burrage K, Dayan P, Richards LJ, Goodhill GJ (2009) Bayesian model predicts the response of axons to molecular gradients. Proc Natl Acad Sci U S A 106: 10296-10301. CrossRef Medline

Mortimer D, Pujic Z, Vaughan T, Thompson AW, Feldner J, Vetter I, Goodhill GJ (2010) Axon guidance by growth-rate modulation. Proc Natl Acad Sci U S A 107:5202-5207. CrossRef Medline

Nagata I, Kawana A, Nakatsuji N (1993) Perpendicular contact guidance of CNS neuroblasts on artificial microstructures. Development 117:401408. Medline

Parent CA, Devreotes PN (1999) A cell's sense of direction. Science 284: 765-770. CrossRef Medline

Pinato G, Raffaelli T, D’Este E, Tavano F, Cojoc D (2011) Optical delivery of liposome encapsulated chemical stimuli to neuronal cells. J Biomed Opt 16:095001. CrossRef Medline

Pinato G, Cojoc D, Lien LT, Ansuini A, Ban J, D’Este E, Torre V (2012) Less than 5 Netrin- 1 molecules initiate attraction but 200 Sema3A molecules are necessary for repulsion. Sci Rep 2:675. CrossRef Medline

Placzek M, Tessier-Lavigne M, Jessell T, Dodd J (1990) Orientation of commissural axons in vitro in response to a floor plate-derived chemoattractant. Development 110:19-30. Medline

Pujic Z, Goodhill GJ (2013) A dual compartment diffusion chamber for studying axonal chemotaxis in 3D collagen. J Neurosci Methods 215:5359. CrossRef Medline

Pujic Z, Giacomantonio CE, Unni D, Rosoff WJ, Goodhill GJ (2008) Analysis of the growth cone turning assay for studying axon guidance. J Neurosci Methods 170:220-228. CrossRef Medline

Rajnicek A, McCaig C (1997) Guidance of CNS growth cones by substratum grooves and ridges: effects of inhibitors of the cytoskeleton, calcium channels and signal transduction pathways. J Cell Sci 110:2915-2924. Medline

Rajnicek A, Britland S, McCaig C (1997) Contact guidance of CNS neurites on grooved quartz: influence of groove dimensions, neuronal age and cell type. J Cell Sci 110:2905-2913. Medline

Rosoff WJ, Urbach JS, Esrick MA, McAllister RG, Richards LJ, Goodhill GJ (2004) A new chemotaxis assay shows the extreme sensitivity of axons to molecular gradients. Nat Neurosci 7:678-682. CrossRef Medline
Roy J, Kennedy TE, Costantino S (2013) Engineered cell culture substrates for axon guidance studies: moving beyond proof of concept. Lab Chip.

Savaskan NE, Plaschke M, Ninnemann O, Spillmann AA, Schwab ME, Nitsch R, Skutella T (1999) Myelin does not influence the choice behaviour of entorhinal axons but strongly inhibits their outgrowth length in vitro. Eur J Neurosci 11:316-326. CrossRef Medline

Sun B, Chiu DT (2003) Spatially and temporally resolved delivery of stimuli to single cells. J Am Chem Soc 125:3702-3703. CrossRef Medline

Sundararaghavan HG, Monteiro GA, Firestein BL, Shreiber DI (2009) Neurite growth in 3D collagen gels with gradients of mechanical properties. Biotechnol Bioeng 102:632-643. CrossRef Medline

Taylor AM, Blurton-Jones M, Rhee SW, Cribbs DH, Cotman CW, Jeon NL (2005) A microfluidic culture platform for CNS axonal injury, regeneration and transport. Nat Methods 2:599-605. CrossRef Medline

Tessier-Lavigne M, Placzek M (1991) Target attraction: are developing axons guided by chemotropism? Trends Neurosci 14:303-310. CrossRef Medline

Tessier-Lavigne M, Placzek M, Lumsden AG, Dodd J, Jessell TM (1988) Chemotropic guidance of developing axons in the mammalian central nervous system. Nature 336:775-778. CrossRef Medline

Tharin S, Kothapalli CR, Ozdinler PH, Pasquina L, Chung S, Varner J, Devalence S, Kamm R, Macklis JD (2012) A microfluidic device to investigate axon targeting by limited numbers of purified cortical projection neuron subtypes. Integr Biol (Camb) 4:1398-1405. CrossRef Medline

Turcu F, Tratsk-Nitz K, Thanos S, Schuhmann W, Heiduschka P (2003) Ink-jet printing for micropattern generation of laminin for neuronal adhesion. J Neurosci Methods 131:141-148. CrossRef Medline

Vielmetter J, Stolze B, Bonhoeffer F, Stuermer CA (1990) In vitro assay to test differential substrate affinities of growing axons and migratory cells. Exp Brain Res 81:283-287. Medline

Vitriol EA, Zheng JQ (2012) Growth cone travel in space and time: the cellular ensemble of cytoskeleton, adhesion, and membrane. Neuron 73: 1068-1081. CrossRef Medline

von Philipsborn AC, Lang S, Bernard A, Loeschinger J, David C, Lehnert D, Bastmeyer M, Bonhoeffer F (2006a) Microcontact printing of axon guidance molecules for generation of graded patterns. Nat Protoc 1:13221328. CrossRef Medline

von Philipsborn AC, Lang S, Loeschinger J, Bernard A, David C, Lehnert D, Bonhoeffer F, Bastmeyer M (2006b) Growth cone navigation in substratebound ephrin gradients. Development 133:2487-2495. CrossRef Medline

von Philipsborn AC, Lang S, Jiang Z, Bonhoeffer F, Bastmeyer M (2007) Substrate-bound protein gradients for cell culture fabricated by microfluidic networks and microcontact printing. Sci STKE 2007:pl6. CrossRef Medline

Walter J, Henke-Fahle S, Bonhoeffer F (1987) Avoidance of posterior tectal membranes by temporal retinal axons. Development 101:909913. Medline

Wittig JH Jr, Ryan AF, Asbeck PM (2005) A reusable microfluidic plate with alternate-choice architecture for assessing growth preference in tissue culture. J Neurosci Methods 144:79-89. CrossRef Medline

$\mathrm{Xu} \mathrm{J,} \mathrm{Rosoff} \mathrm{WJ,} \mathrm{Urbach} \mathrm{JS,} \mathrm{Goodhill} \mathrm{GJ} \mathrm{(2005)} \mathrm{Adaptation} \mathrm{is} \mathrm{not} \mathrm{required}$ to explain the long-term response of axons to molecular gradients. Development 132:4545-4552. CrossRef Medline

Yam PT, Langlois SD, Morin S, Charron F (2009) Sonic hedgehog guides axons through a noncanonical, Src-family-kinase-dependent signaling pathway. Neuron 62:349-362. CrossRef Medline

Yam PT, Kent CB, Morin S, Farmer WT, Alchini R, Lepelletier L, Colman DR, Tessier-Lavigne M, Fournier AE, Charron F (2012) 14-3-3 proteins regulate a cell-intrinsic switch from sonic hedgehog-mediated commissural axon attraction to repulsion after midline crossing. Neuron 76:735-749. CrossRef Medline

Zicha D, Dunn GA, Brown AF (1991) A new direct-viewing chemotaxis chamber. J Cell Sci 99:769-775. Medline 